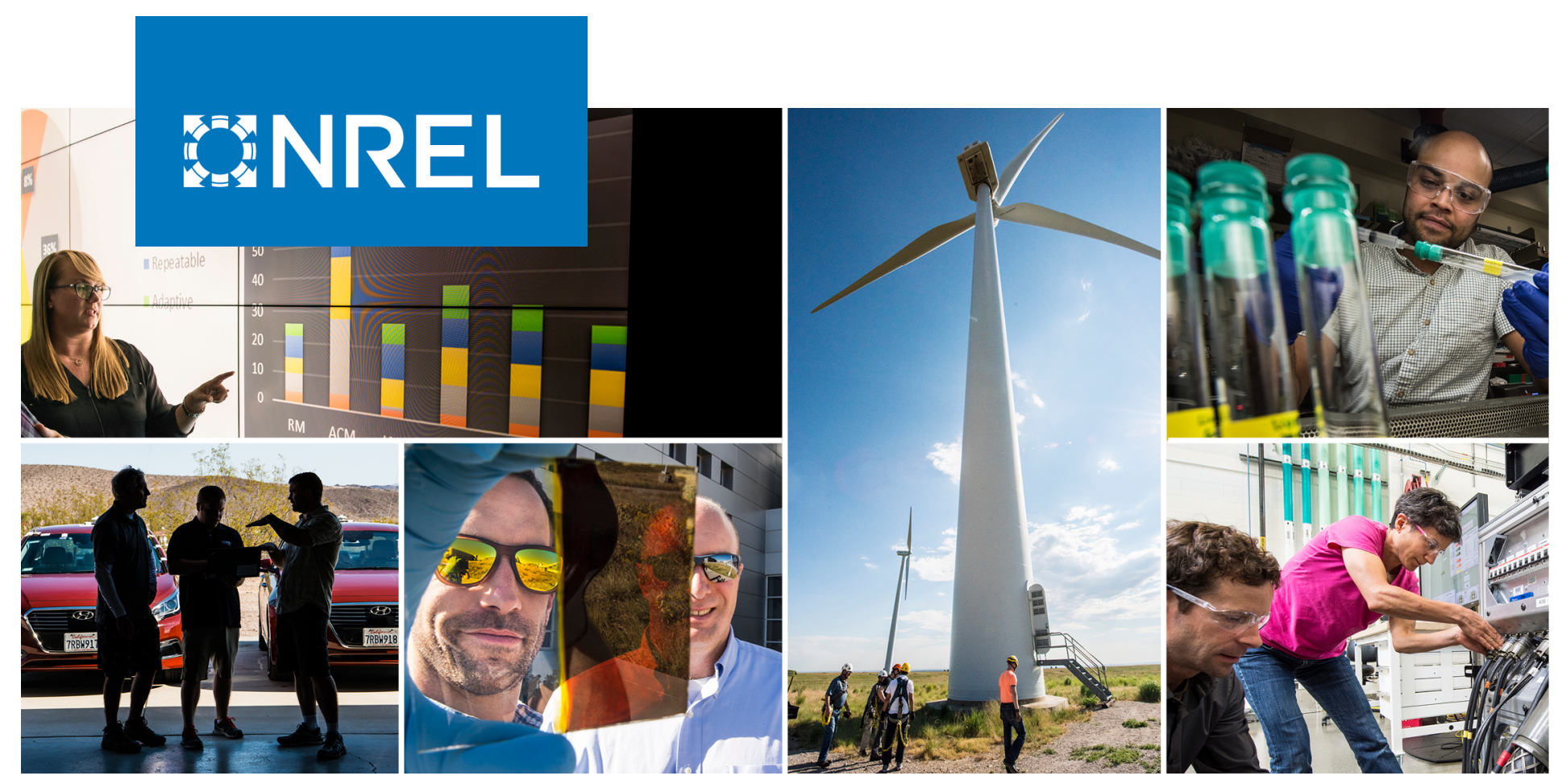

Using Spectral Measurements to Characterize Solar Reference Cells on a Two-Axis Tracker

\title{
Preprint
}

Frank Vignola, ${ }^{1}$ Josh Peterson, ${ }^{1}$ Rich Kessler, ${ }^{1}$ Aron Habte, ${ }^{2}$ Peter Gotseff, ${ }^{2}$ Manajit Sengupta, ${ }^{2}$ and Fotis Mavromatakis ${ }^{3}$

1 University of Oregon

${ }^{2}$ National Renewable Energy Laboratory

${ }^{3}$ Hellenic Mediterranean University

Presented at the 47th IEEE Photovoltaic Specialists Conference (PVSC-47) June 15-August 21, 2020

NREL is a national laboratory of the U.S. Department of Energy Office of Energy Efficiency \& Renewable Energy

Operated by the Alliance for Sustainable Energy, LLC

This report is available at no cost from the National Renewable Energy Laboratory (NREL) at www.nrel.gov/publications.
Conference Paper

NREL/CP-5D00-76896

September 2020 


\title{
BNREL
}

\section{Using Spectral Measurements to Characterize Solar Reference Cells on a Two-Axis Tracker}

\section{Preprint}

\author{
Frank Vignola, ${ }^{1}$ Josh Peterson, ${ }^{1}$ Rich Kessler, ${ }^{1}$ \\ Aron Habte, ${ }^{2}$ Peter Gotseff, ${ }^{2}$ Manajit Sengupta, ${ }^{2}$ and \\ Fotis Mavromatakis ${ }^{3}$ \\ 1 University of Oregon \\ 2 National Renewable Energy Laboratory \\ ${ }^{3}$ Hellenic Mediterranean University
}

\section{Suggested Citation \\ Vignola, Frank, Josh Peterson, Rich Kessler, Aron Habte, Peter Gotseff, Manajit Sengupta, and Fotis Mavromatakis. 2020. Using Spectral Measurements to Characterize Solar Reference Cells on a Two-Axis Tracker: Preprint. Golden, CO: National Renewable Energy Laboratory. NREL/CP-5D00-76896. https://www.nrel.gov/docs/fy20osti/76896.pdf.}

(C) 2020 IEEE. Personal use of this material is permitted. Permission from IEEE must be obtained for all other uses, in any current or future media, including reprinting/republishing this material for advertising or promotional purposes, creating new collective works, for resale or redistribution to servers or lists, or reuse of any copyrighted component of this work in other works.

NREL is a national laboratory of the U.S. Department of Energy Office of Energy Efficiency \& Renewable Energy Operated by the Alliance for Sustainable Energy, LLC

This report is available at no cost from the National Renewable Energy Laboratory (NREL) at www.nrel.gov/publications.

Contract No. DE-AC36-08GO28308
Conference Paper

NREL/CP-5D00-76896

September 2020

National Renewable Energy Laboratory 15013 Denver West Parkway Golden, CO 80401

303-275-3000 • www.nrel.gov 


\section{NOTICE}

This work was authored in part by the National Renewable Energy Laboratory, operated by Alliance for Sustainable Energy, LLC, for the U.S. Department of Energy (DOE) under Contract No. DE-AC36-08GO28308. Funding provided by U.S. Department of Energy Office of Energy Efficiency and Renewable Energy Solar Energy Technologies Office. The views expressed herein do not necessarily represent the views of the DOE or the U.S. Government.

This report is available at no cost from the National Renewable Energy Laboratory (NREL) at www.nrel.gov/publications.

U.S. Department of Energy (DOE) reports produced after 1991 and a growing number of pre-1991 documents are available free via www.OSTI.gov.

Cover Photos by Dennis Schroeder: (clockwise, left to right) NREL 51934, NREL 45897, NREL 42160, NREL 45891, NREL 48097, NREL 46526.

NREL prints on paper that contains recycled content. 


\section{Using Spectral Measurements to Characterize Solar Reference Cells on a Two-Axis Tracker}

\author{
Frank Vignola \\ University of Oregon \\ Solar Radiation Monitoring Lab \\ Eugene, Oregon, USA \\ fev@uoregon.edu
}

\author{
Josh Peterson \\ University of Oregon \\ Solar Radiation Monitoring Lab \\ Eugene, Oregon, USA \\ jpeters4@uoregon.edu
}

\author{
Rich Kessler \\ University of Oregon \\ Solar Radiation Monitoring Lab \\ Eugene, Oregon, USA \\ rkessler@uoregon.edu
}

\author{
Aron Habte \\ National Renewable Energy \\ Laboratory \\ Golden, Colorado USA \\ Aron.Habte@nrel.gov
}

\author{
Peter Gotseff \\ National Renewable Energy Laboratory \\ Golden, Colorado USA \\ Peter.Gotseff@nrel.gov
}

\author{
Manajit Sengupta \\ National Renewable Energy Laboratory \\ Golden, Colorado USA \\ Manajit.Sengupta@nrel.gov
}

\author{
Fotis Mavromatakis \\ Dept. of Electrical \& Computer Engineering \\ Hellenic Mediterranean University \\ Estavromenos, Crete, Greece \\ fotis@hmu.gr
}

\begin{abstract}
A study is commencing relating the spectral responsivity of reference cells in the field to changing spectral distribution during the day. Initial results indicate that measurements of the incident spectral distribution can be used to match results of reference cell measurements on a two-axis tracker with a standard deviation of $\pm \mathbf{0 . 2 5 \%}$ under clear-sky conditions. Initial results are provided. As more data are obtained covering a variety of field conditions and locations, the robustness of these results will be tested.
\end{abstract}

Keywords - reference cell, spectral, tracker, photodiode-based pyranometer

\section{I.INTRODUCTION}

The National Renewable Energy Laboratory (NREL) and the University of Oregon Solar Radiation Monitoring Laboratory (UO SRML) are jointly evaluating the performance of several reference cells on two-axis trackers using spectral measurements and Class A pyranometers. The data became available from NREL on May 1, 2020 and a similar experiment is being installed in Eugene, Oregon in June, 2020. This is part of a project to understand and characterize the measurements from reference cells and photodiode-based pyranometers to facilitate the comparisons of field experiments made using a variety of instruments.

The availability of ground-based irradiance measurements is limited compared to the coverage of satellite-derived irradiance data, however, ground-based measurements can provide measurements at shorter timescales and ones that are more specific for a given photovoltaic (PV) site. Ground-based data can also be made available in real time to assist station operation.

Reference cells and photodiode-based pyranometers have been studied previously [1]-[4] and have shown systematic biases when compared to high-quality thermopile-based pyranometers. The output of reference cells and photodiodebased pyranometers are dependent on the spectral distribution of incident radiation, the temperature of the sensors, and the angle-of-incident (AOI) effects, dependences that are similar to those found in PV modules. Knowledge of these dependencies

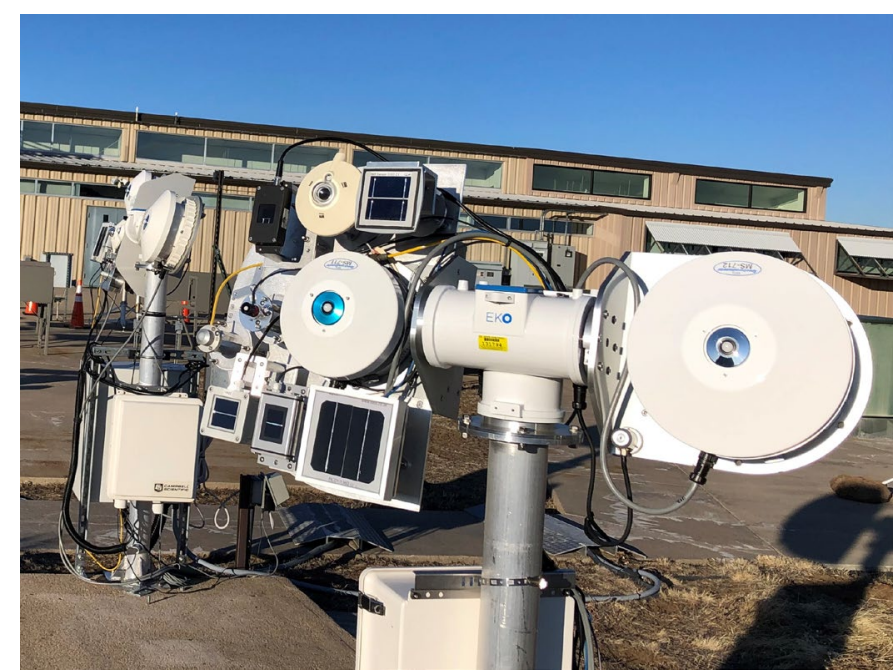

Fig. 1 Two-axis tracker and instruments at NREL. A one-axis tracker with similar instruments is in the background.

can help when estimating the incident irradiance from reference cell measurements.

This study also aims to examine the performance of a variety of reference cells on two-axis trackers at the high altitude facility in Golden, Colorado and in the verdant Willamette Valley in Eugene, Oregon. Also mounted on the trackers are spectroradiometers and Class A pyranometers (see Fig. 1). The two-axis tracker provides a platform with the instruments pointed directly at the sun, hence minimizing the AOI effects. (There are some AOI effects from diffuse and ground reflected irradiance especially when the sun is within $10^{\circ}$ of the horizon.) 


\section{II.ABOUT THE DATA}

In Golden, Colorado the platform includes FRA, ATO, IKS, NES, IMT, and EET reference cells as well as a LI-COR LI200R and a Kipp \& Zonen SP Lite2 pyranometer. At Eugene, Oregon the platform includes RC18, IKS, NES, IMT, and EET reference cells as well as a LI-COR LI-200R and a Kipp \& Zonen SP Lite2 pyranometer. By testing the output of the reference cells against spectral distributions for two diverse sites, site-specific or equipment specific effects can be estimated. The data from these experiments are uploaded to NREL's Measurement and Instrumentation Data Center as they are gathered.

Reference solar cells are used to evaluate the performance of photovoltaic (PV) systems. The advantage of using references cells is that they are similar in structure and material to PV modules being evaluated; therefore, reference cells will have the same spectral response and AOI response as PV modules. The disadvantages are that they are not pyranometers designed to measure incident solar radiation, and their spectral response and AOI response differ from Class A pyranometers. Models used to estimate solar irradiance on different surfaces and orientations are based on high-quality measurements made using Class A pyranometers and pyrheliometers. This makes it difficult to use reference cell measurements for comparisons or validation with models or measurements made to using irradiance data obtained from Class A instruments.

NREL and UO SRML have been studying the performance of reference cells and pyranometers on horizontal, fixed, and one-axis tracking surfaces [1-4]. Based on these studies, it was decided to instigate two-axis tracking systems both Golden and Eugene to evaluate the performance of a variety of reference cells and to obtain a more general understanding of the reference cells and the uncertainties involved.

\section{III.DATA}

The data comes from several reference cells mounted on a two-axis tracker along with a Class A Kipp \& Zone CMP 22 pyranometer and EKO spectroradiometers with a combined range from 290 to $1650 \mathrm{~nm}$. In Eugene, the EKO spectroradiometer has a range from 300 to $1100 \mathrm{~nm}$. The CMP 22 pyranometer acts as a reference pyranometer. A comparison of an IMT reference cell to the reference pyranometer is shown in Fig. 2 for two clear-sky periods, the morning of May 3, 2020, and the afternoon of May 4, 2020.

In the late afternoon and early morning (solar zenith angle $=80^{\circ}$ to $85^{\circ}$ ), the temperatures are about $25 \mathrm{C}$ and the differences are related to different spectral distributions and different ground reflected and horizon irradiance.

The relationship between IMT output and irradiance is given in Eq. 1.

$$
I M T=K \cdot R(\lambda, T) F(A O I)
$$

where $R(\lambda, T)$ is the responsivity of the reference cell summed over all wavelengths $(\lambda)$. The effect of temperature $(T)$ on the reference cell responsivity is also wavelength dependent and is included in the model of $R(\lambda, T)$ [3], [4]. The constant $K$ scales the spectral responsivity of the reference cell. $F(A O I)$ describes the deviation from a cosine response as a function of the AOI).

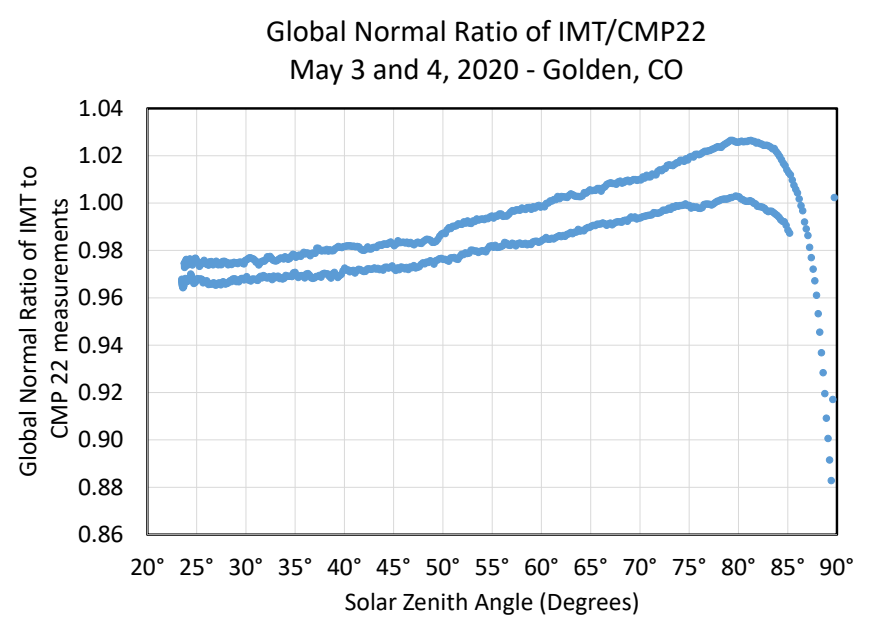

Fig. 2 Plot of the ratio of the global normal irradiance from a CMP 22 pyranometer and an IMT reference cell during clear-sky periods on May 3, 2020 and May 4, 2020. Instruments mounted on a two-axis tracker.

For normal incidence irradiance on a two-axis tracker $F(A O I)=$ 1.

Fig. 3 shows the ratio of $R(\lambda, T)$ calculated using the spectral distribution measured by the spectroradiometers to the measured output of the IMT reference cell during clear-sky periods. The reference cell and spectroradiometer are both mounted on the two-axis tracker.

The calculation of average responsivity also involved a model of the spectral temperature dependence of the reference cell [2]-[4]. The average temperature response of a reference is usually the only parameter that is measured. In the case of the IMT reference cell, the average temperature dependence is proportional to 0.0008 times the difference between the reference cell temperature and $25^{\circ} \mathrm{C}$.

A comparison using the spectral verses fixed temperature dependence is shown in Fig. 4. When the reference cell is near $25 \mathrm{C}$, the two calculations agree. For this example this occurs early in the morning and late in the afternoon when the solar

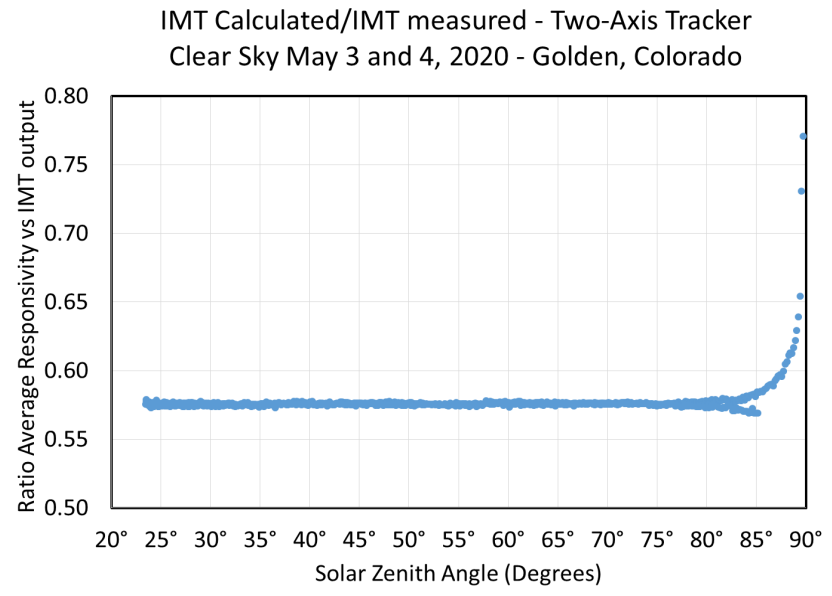

Fig. 3 Ratio of calculated responsivity of the IMT to IMT output on a two-axis tracker under clear-sky conditions. 


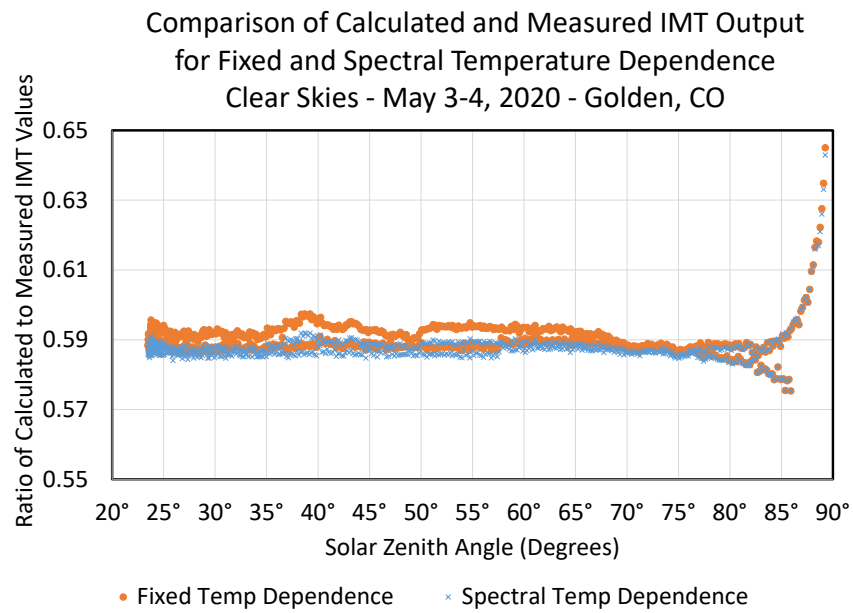

Fig. 4 Ratio of calculated responsivity of the IMT to IMT output on a two-axis tracker under clear-sky conditions using fixed and spectral temperature dependences.

zenith angle is between $80^{\circ}$ and $85^{\circ}$. Using the spectral temperature dependence reduces the standard deviation by approximately $40 \%$ as compared to a fixed temperature dependence.

\section{CONCLUSIONS}

Using Eq. 1 and information in Fig. 3, the value of $K$ determined from $20^{\circ}$ to $80^{\circ}$ is 0.5872 with a standard deviation of \pm 0.0015 or approximately $\pm 0.25 \%$ for the clear-sky period during these 2 days. This illustrates that the average responsivity of a monocrystalline reference cell can be modeled accurately up to $80^{\circ}$ if the spectral distribution is known and the instrument is on a two-axis tracker (point directly to the sun).

Assuming ground reflected irradiance has only a small contribution, this method can be adopted to other surfaces and orientations if one has a solid model of $\mathrm{F}(\mathrm{AOI})$ given information on incident spectral irradiance. More usefully, one should be able to extract the average responsivity of the reference cell and use that information to estimate PV system performance.

Although spectral irradiance data are seldom available, models for spectral irradiance do exist, and with the data provided by these experiments, spectral models can be tested; therefore, it should be possible to covert reference cell measurements into irradiance values.

\section{ACKNOWLEDGMENTS}

The UO Solar Radiation Monitoring Laboratory would like to thank the National Renewable Energy Laboratory as well as the Bonneville Power Administration, Energy Trust of Oregon, and Portland General Electric for the support that makes this work possible. This work was authored in part by Alliance for Sustainable Energy, LLC, the manager and operator of the National Renewable Energy Laboratory for the U.S. Department of Energy (DOE) under Contract No. DE-AC3608GO28308.via the U.S. Department of Energy under Contract No. DE-AC36-08GO28308. Funding provided by U.S.
Department of Energy Office of Energy Efficiency and Renewable Energy Solar Energy Technologies Office. The views expressed in the article do not necessarily represent the views of the DOE or the U.S. Government. The U.S. Government retains and the publisher, by accepting the article for publication, acknowledges that the U.S. Government retains a nonexclusive, paid-up, irrevocable, worldwide license to publish or reproduce the published form of this work, or allow others to do so, for U.S. Government purposes.

\section{REFERENCES}

[1] F. Vignola, C. Chiu, J. Peterson, M. Dooraghi, M. Sengupta, "Comparison and analysis of instruments measuring plane-of array irradiance for one-axis tracking PV systems", IEEE PVSC Conference, Washington D.C., 2017

[2] F. Vignola, J. Peterson, M. Dooraghi, M. Sengupta, F. Mavromatakis, "Comparison of Pyranometers and Reference Cells on Fixed and One-Axis Tracking" American Solar Energy Society Conference Denver, Colorado October 9-12, 2017

[3] Frank Vignola, Josh Peterson, Rich Kessler, Mike Dooraghi, Manajit Sengupta, and Fotis Mavromatakis, "Evaluation of Photodiode-based Pyranometers and Reference Solar Cells on a Two-Axis Tracking System", World Conference on Photovoltaic Energy Conversion Waikoloa, Hawaii, June 10-15, 2018

[4] Frank E Vignola, Josh Peterson, Rich Kessler, Vikram Sandhu, Aron Habte, Manajit Sengupta. "Improved Field Evaluation of Reference Cell Using Spectral Measurements", IEEE PVSC Conference, Chicago, IL, 2019 